\title{
RARE CASE REPORT: WERNER'S SYNDROME - PREMATURE AGING SYNDROME SEEN IN TWO SISTERS
}

\author{
M.G. Gopal' ${ }^{1}$ Kavya Raju Nayak², Sharath Kumar B.C ${ }^{3}$, Ramesh Mㄴ, Nandini A.S ${ }^{5}$
}

\section{HOW TO CITE THIS ARTICLE:}

MG Gopal, Kavya Raju Nayak, Sharath Kumar BC, Ramesh M, Nandini AS. “Rare case report: Werner's syndrome premature aging syndrome seen in two sisters". Journal of Evolution of Medical and Dental Sciences 2013; Vol. 2, Issue 45, November 11; Page: 8864-8868.

\begin{abstract}
Werner's syndrome is a premature aging syndrome with autosomal recessive mode of inheritance. It is a rare case, hence early identification of disease and genetic counseling is important. AIM: To describe the clinical features of Werner's Disease in two siblings. CLINICAL PRESENTATION: A 34 year old female came with recurrent ulcers on lower limb, she was operated for bilateral cataract, hypopigmentation in B/L extensor surface of arm and waist, absence of axillary and pubic hair, loss of subcutaneous fat and the patient appeared old. Her younger sister, 33year old female came with similar complaints but less severe and had diabetes mellitus. H/O consanguineous marriage in parents. RESULT: Skin biopsy: Epidermis was thinned out, appendages are sparse and dermis showed thick hyalinised collagen. CONCLUSION: With Clinical features of premature aging, h/o consanguineous marriage, positive family history a diagnosis of Werner's disease was made.
\end{abstract}

INTRODUCTION: Werner's syndrome is a progeroid syndrome. It is an autosomal recessive disorder characterized by an accelerated aging process after puberty. It is considered as an genomic instability syndrome. Mutation are present in DNA helicase gene. Cutaneous changes like atrophy, loss of subcutaneous fat, wrinkling, canities, loss of hair, defective pigmentation, sclerosis and ulceration. Diabetes Mellitus, posterior subcapsular cataract, atheroma and malignancies develop at an early age. ${ }^{2}$ This article describes the clinical features of Werner's syndrome in two siblings.

CASE REPORT: A 34 year old married nulliparous female came with recurrent ulcers on lower limb, the recurrent ulcers were seen on bony prominences like medial malleolus, she was operated for cataract of both the eyes 10 years back, depigmentation was present on in B/L elbows and extensor surface of arm, around the waist area, she had sparse grey hair on the scalp, absence of axillary and pubic hair, the face appeared aged, with beaked nose, loss of subcutaneous fat and the patient appeared old. Patient had poliosis of eyelashes her legs and hands were very slender and spindle shaped with loss of subcutaneous fat, the skin was taut stretched tightly over the bone with sclerodermatous skin changes. Obstetric History: Gravida -0, Para- 0, Living -0.Menstrual history: attained menopause 2 years back, early attainment of menopause. Short stature $140 \mathrm{~cm}$, patients weight was $25 \mathrm{kgs}$.Her younger sister, 33year old female came with similar complaints, sparse hair, mottled pigmentation, dry atrophic skin, loss of subcutaneous fat, prematurely aged appearance, bird like facies, cataract of both eyes for which she was operated, H/O diabetes mellitus since 10 years on treatment, all her complaints were less severe compared to her elder sister. H/O consanguineous marriage in parents. Out of the five siblings, 1 male and 4 female, two of them were affected, rests of the siblings were normal. Complete haemogram: both the sisters were anaemic, ANA was normal in both, X-ray of the limbs was normal in both. Skin Biopsy From younger affected 
sibling showed: Atrophied epidermis, appendages are sparse and dermis showed thick hyalinised collagen.

RESULTS: With Clinical features of premature aging, h/o consanguineous marriage, positive family history and biopsy reports a diagnosis of Werner's disease was made.

DISCUSSION: Werner's syndrome is a rare autosomal recessive disorder. The syndrome is characterized by premature ageing with sclerodermatous skin changes, subcutaneous calcification, short stature, prematurely aged facies, premature arteriosclerosis, diabetes mellitus and a predisposition to malignancy. Werner's syndrome was initially described by Werner's in 1904, when he reported four cases of brothers and sisters with symptoms and signs including juvenile cataract, pachyderma-like alteration of the extremities, short stature, premature aging of the face, juvenile grey hair, and genital hypoplasia. The syndrome is due to an autosomal recessive gene with a gene frequency of 1-5 per 1000 population. ${ }^{1}$

Etiology: Progeroid syndromes are characterized by clinical features mimicking physiological ageing.These syndromes are clinically and genetically heterogeneous and most of them, including Werner syndrome and Hutchison- Gilford progeria are known as segmental ageing syndromes. Werner's syndrome is caused by mutations in WRN (RECQL2), a DNA helicase gene on 8p12-p11.2 $[2,3]$.

Clinical features: The cutaneous features of Werner's syndrome include sclerodermatous skin changes, particularly on the face and extremities, and subcutaneous calcification. The legs are thin and spindle shaped with pigmentation, telangiectasia and keratosis over the pressure points which can lead to indolent ulcers. The face has a prematurely aged appearance with beaking of the nose. Hair may be sparse and prematurely grey. Stature is short with slender limbs. Patients tend to develop early arteriosclerosis, diabetes mellitus, osteoporosis and hypogonadism, and are at risk of cataracts and retinal degeneration. ${ }^{4}$ Werner's syndrome patients are predisposed to developing malignancies, in particular myeloid disorders, meningiomas, melanomas, thyroid cancers and osteosarcomas. ${ }^{5}$

Treatment: Only symptomatic treatment can be provided. Recurrent ulcers of the foot may require amputation.

CONCLUSION: With Clinical features of premature aging, h/o consanguineous marriage, positive family history a final diagnosis of Werner's disease was made. We would like to report this case for its rarity and early identification is important to rule out any associated internal malignancy, cataract and systemic diseases at early age and also it is important to give genetic counseling to these patients.

\section{BIBLIOGRAPHY:}

1. Yu CE, Oshima J, Wijsman EM, Nakura J, Miki T, Piussan C, et al. Mutations in the concensus helicase domains of the Werner's syndrome gene. Werner's Syndrome Collaborative Group. Am J Hum Genet 1997;60:330-41. 
2. A.D. Irvine \& J.E. Mellerio. Genetics and Genodermatosus In: Burns T, Breathnach S, Cox N, Griffiths C, eds. Rook's Textbook of Dermatology, 8th edition. Oxford: Wiley Blackwell publication 2010:15.1 to 15.97

3. Goto M, Imamura 0, Kuromitsu J et al. Analysis of helicase gene mutations in Japanese Werner's syndrome patients. Hum Genet 1997; 99: 191-3.

4. 4.Goto M, Tanimoto K, Horiuchi Y, Sasazuki T. Family analysis of Werner's syndrome: a survey of 42 Japanese families with a review of the literature. ClinGenet 1981;19:8-15.

5. Goto M, Miller RW, Ishikawa Y, Sugano H. Excess of rare cancers in Werner syndrome (adult progeria). Cancer Epidermiol Biomarkers Prev 1996; 5:239-4.
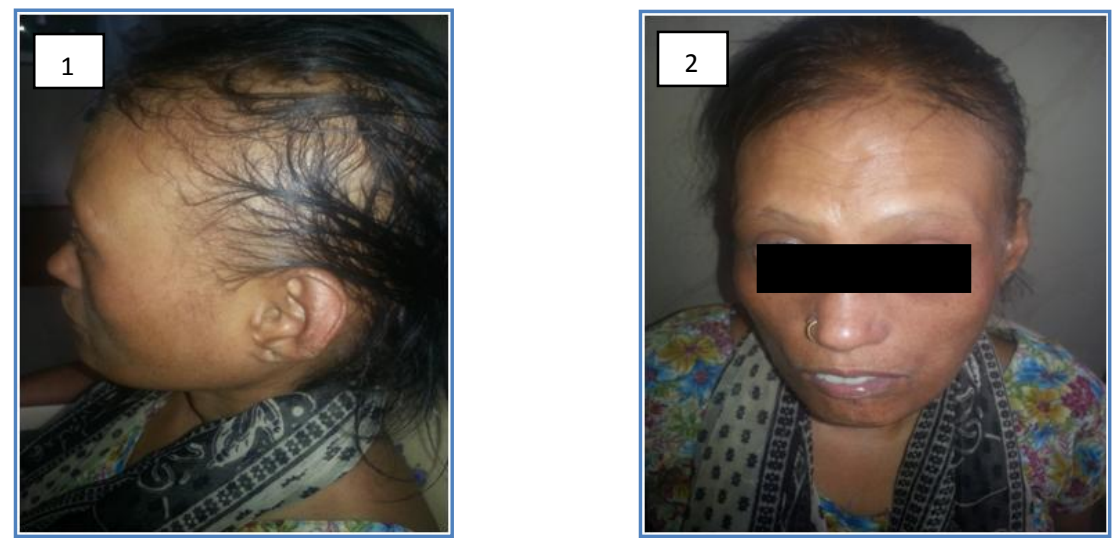

Fig. 1: Spare hair, sparse eyebrows, loss of subcutaneous fat, premature aged look in the younger sibling.

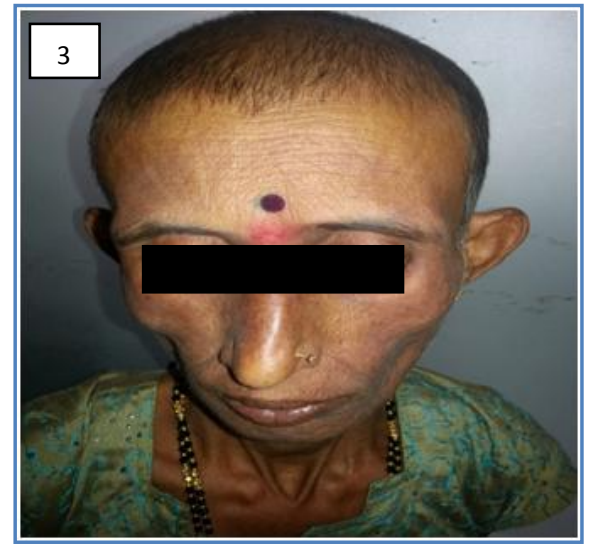

Fig. 3: Sparse hair, poliosis of eyelashes, premature greying of hair loss of buccal fat, aged appearance, wrinkles and bird like facies in the elder sister. 


\section{CASE REPORT}
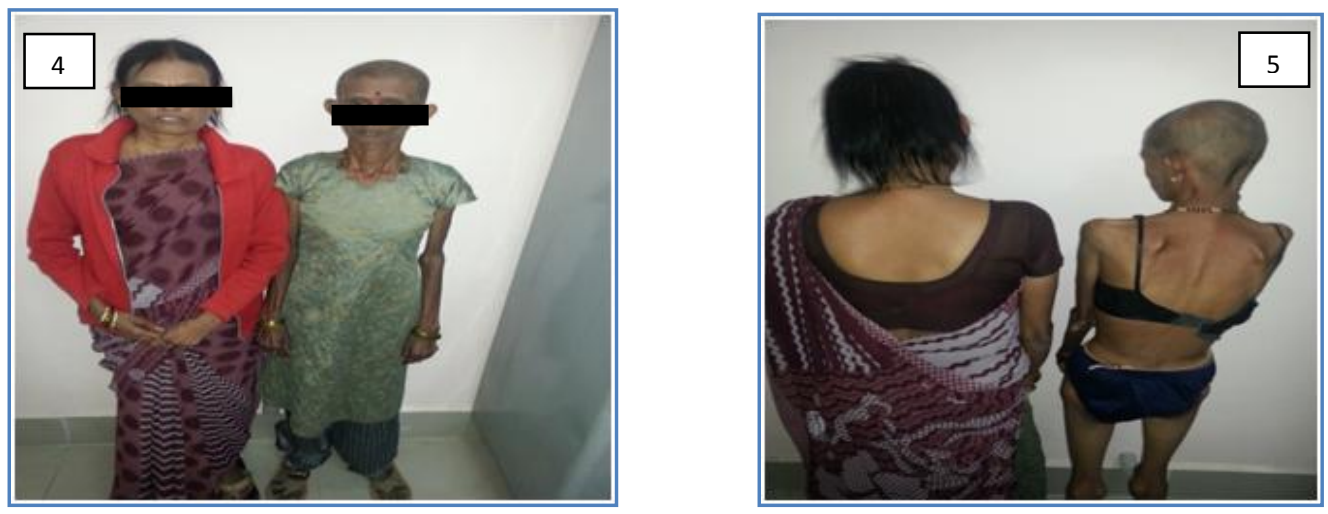

Fig. 4 and 5: Premature aged appearance in both the siblings
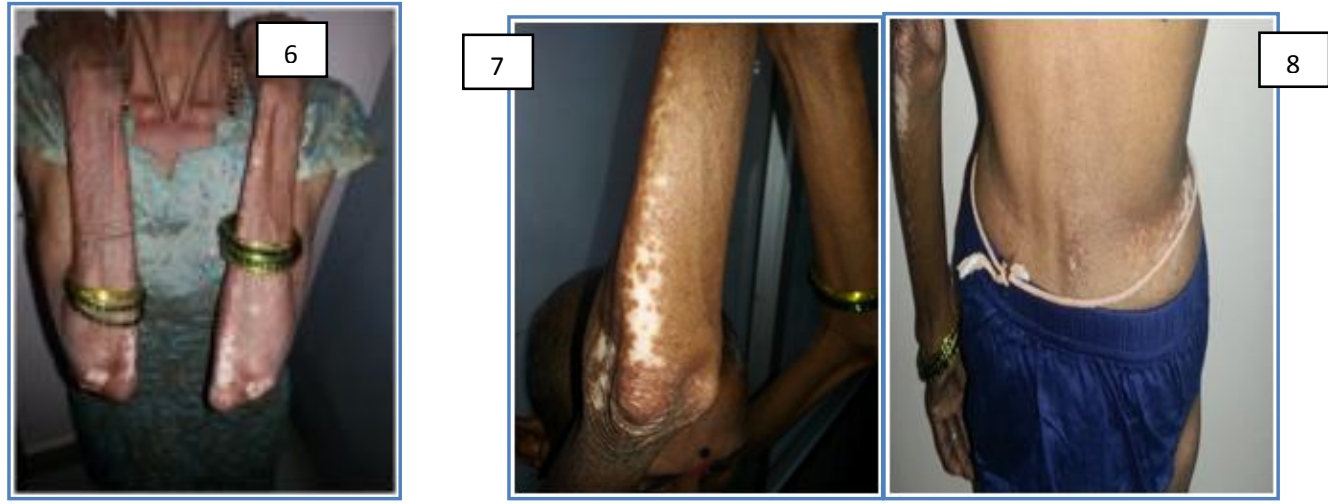

Fig. 6, 7 \& 8: Depigmented macules on the extensor aspect of upper limb and waist area in elder sibling.
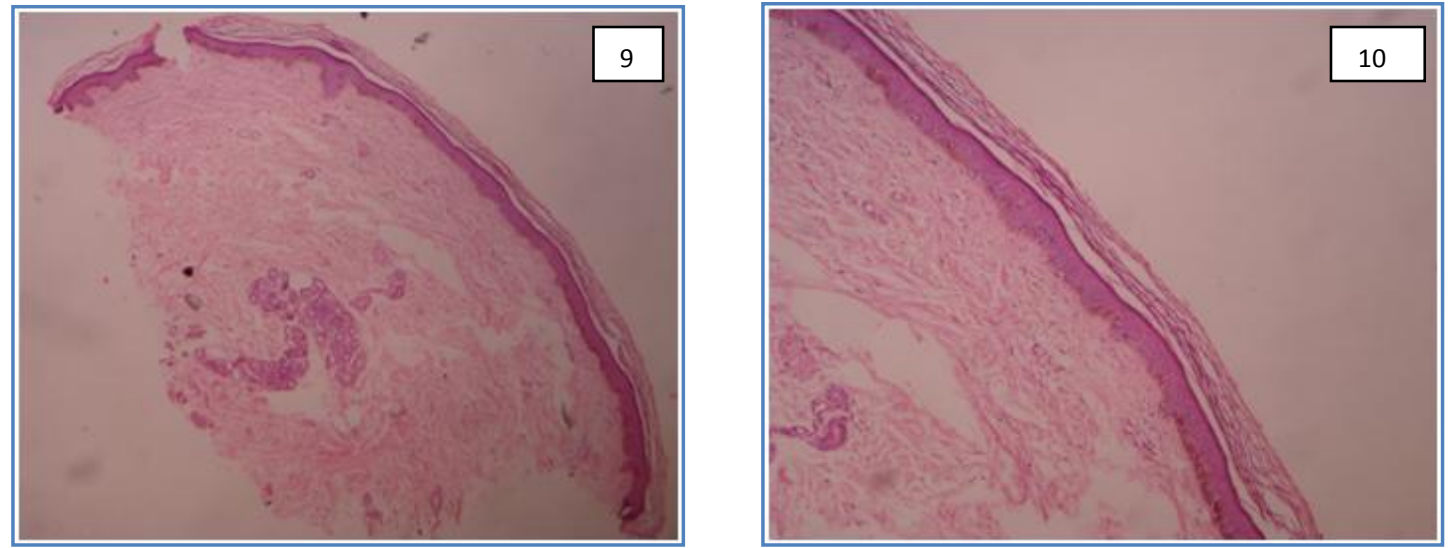

Fig. 9 \& 10: Thin atrophic epidermis with loss of rete ridges. hyalinization of collagen in dermis, loss of pilosebacous units. 


\section{AUTHORS:}

1. M.G. Gopal

2. Kavya Raju Nayak

3. Sharath Kumar B.C.

4. Ramesh M.

5. Nandini A.S.

\section{PARTICULARS OF CONTRIBUTORS:}

1. Professor and Head of Department, Department of Dermatology, Kempegowda Institute of Medical Sciences, Bangalore.

2. Post Graduate, Department of Dermatology, Kempegowda Institute of Medical Sciences, Bangalore.

3. Professor, Department of Dermatology, Kempegowda Institute of Medical Sciences, Bangalore.
4. Associate Professor, Department of Dermatology, Kempegowda Institute of Medical Sciences, Bangalore.

5. Assistant Professor, Department of Dermatology, Kempegowda Institute of Medical Sciences, Bangalore

\section{NAME ADDRESS EMAIL ID OF THE CORRESPONDING AUTHOR:}

Dr. Kavya Nayak,

c/o Shushrut Adigon,

71, Maruthi Layout,

Vijaynagar - 560040 .

Email - drkavyanayak@gmail.com

Date of Submission: 27/10/2013.

Date of Peer Review: 28/10/2013.

Date of Acceptance: 29/10/2013.

Date of Publishing: 08/11/2013 